\title{
PLAASLIKE BESTUUR EN SY ROL IN FISIESE BEPLANNING
}

\section{Inleiding}

Somaar uit die staanspoor wil ek verduidelik dat my benadering miskien vir sommige van $u$ as te prakties en van te algemene aard mag voorkom en $u$ moontlik sou verkies het dat ek meer moes uitwei oor die tegnieke en die beginsels van beplanning. Daardie aspekte laat ek egter aan die persone oor wat beter gekwalifiseer is om daaroor te praat as ek. Dit beteken egter nie dat ek, en ander soos ek, die aanvaarde en beproefde beginsels vir goeie beplanning kan ignoreer nie. Ek wil egter met hierdie inleidende woorde volstaan en dit aan $u$ oordeel oorlaat om te besluit of $u$ met hierdie benadering van my saamstem. Indien u nie met my saamstem nie, dan vertrou ek dat wat ek hier te sê het $\mathbf{u}$ minstens sal prikkel en $u$ miskien sal aanspoor om die saak te stel soos $u$ dit sien.

Soos $\mathrm{u}$ weet maak ons Staatkundige patroon voorsiening vir 'n drievlak-vorm van regering, naamlik, die Sentrale Regering, die Provinsiale Administrasie en die Plaaslike Besture. $\mathrm{U}$ sal met my saamstem, as ek bo kan begin, dat dit nooit van die Sentrale Regering verwag kan word om in die algemeen op die Plaaslike Bestuursvlak te beplan nie - daarvoor is die Sentrale Regering te ver verwyder van die werklike toneel en sy masjinerie te ontoereikend. Dieselfde kan ook, maar miskien in 'n mindere mate, van die Provinsies gesê word wat stadsbeplanning betref. Hierbenewens is daar ook vir die Provinsies en die Sentrale Regering so 'n groot taak op die streeks- en nasionale vlak om te behartig dat hulle asnog, selfs nie eers by benadering, daarin kon slaag om dit te verrig nie.

Sy Edele adv. Haak, Minister van Beplanning, het hierdie gedagte baie duidelik gestel tydens ' $n$ toespraak in Februarie 1964, hier te Potchefstroom. Hy het toe onder andere verklaar dat hy die beplanningsbeginsel van samewerking op sentrale, provinsiale en plaaslike vlakke ten sterkste ondersteun en het verder die volgende gesê:

„Onder die huidige beplanningstelsel beplan die staat hoofsaaklik op nasionale vlak, die provinsies op hul terrein in die streke; en die plaaslike besture op hulle eie ter- 
rein. Hierdie stelsel is histories eie aan ons en pas in by ons staatkundige opset."

En verder:

„Dit is trouens 'n basiese beginsel van die drievlakbeplanning wat ek voorheen vir $u$ geskets het dat ' $n$ mens by die geheel begin en dan afkom na die besonderhede. Die Sentrale Regering moet eers die gekoördineerde geheelplan afbaken voordat dit oorgegee kan word aan die Provinsies vir streekbeplanning binne daardie groter raamwerk."

Ek wil egter terselfdertyd daarop wys dat dit 'n onverstandige persoon of plaaslike bestuur sal wees wat vir die Staat en die Provinsie die reg sou wou ontsê om in te meng waar, na die mening van die Staat, die optrede van so 'n plaaslike bestuur indruis teen Staatsbeleid of die openbare belang, veral waar so 'n plaaslike bestuur sou versuim om die regeringsbeleid uit te voer. In die beplanning van ons stede en dorpe geniet die plaaslike bestuur slegs vryheid van beweging en outonomie in soverre as wat hulle nie in botsing kom met sentrale regerings- of provinsiale-beleid nie. Dit is dus vanselfsprekend dat die plaaslike bestuur deeglik op hoogte sal moet bly van die beleid van genoemde owerhede. Voortvloeiend hieruit is dit dan ook voor-die-hand-liggend dat daar die nouste koördinasie tussen die drie regeringsvlakke moet wees, want indien dit nie gebeur nie kan verwag word dat daar 'n verspilling van arbeid en kapitaal moet plaasvind as gevolg van oorvleueling en vrugtelose werk.

$\mathrm{Ek}$ is oortuig dat die beste stelsel vir beplanning in ons land die drievlakstelsel is. Die Plaaslike Bestuur is uiteraard die geskikste liggaam om stadsbeplanning uit te voer omdat hy vertroud is met plaaslike omstandighede en in die nouste voeling met die gemeenskap verkeer. Die Provinsiale Administrasie is die aangewese instansie om die beplanning van plaaslike besture te koördineer en toe te sien dat die neergelegde beleid toegepas en uitgevoer word. Die Provinsie beskik oor die beste organisasie en meeste inligting om hom in staat te stel om streekbeplanning te onderneem. Die Staat kan dan sy kragte aanwend om beleid te formuleer, langtermynbeplanningsprojekte van algemene aard aan te pak en te verseker dat beplanning deur die Provinsies onderling ingepas word en in ooreenstemming is met landsbeleid. Ek wil herhaal, hoe gouer drievlakbeplanning in ons land 'n 
werklikheid word en oorvleueling uitgeskakel word, des te gouer sal ons die vrugte van doeltreffende beplanning in ons stede, dorpe en streke kan pluk.

\section{Die plaaslike bestuurstelsel}

Die plaaslike bestuur vervul 'n belangrike rol in ons hedendaagse samelewing. Dit is die vorm van bestuur waarmee die "man op straat" die meeste in aanraking kom (ek bedoel nie daardie elemente wat so nou en dan met die gereg kennis maak nie). Dit is die vorm van bestuur wat normaalweg die meeste beperkings op ons plaas, waaroor daar gewoonlik die meeste klagtes gehoor word maar ook waarin elke burger 'n verteenwoordiging het en wat hom die nouste raak elkeen kan die debatte wat oor plaaslike sake gevoer word verstaan. In ander woorde, dit is die intiemste vlak van regering.

Ons stelsel van plaaslike bestuur is reeds baie breed en stewig uitgebou en vorm 'n goeie basis vir bestuur. In ons land is plaaslike besture miskien nie so sterk as in oorsese lande nie, waar stede en dorpe uitgebreide magte en bevoegdhede besit en daar ' $n$ sterk gevoel van plaaslike onafhanklikheid bestaan as gevolg van 'n historiese groeiproses. Ek is van mening dat op hierdie stadium van ons ontwikkeling dit eerder as ' $n$ voordeel beskou kan word om nie so 'n toestand hier te hê nie, omdat daar heelwat probleme uit kan voortspruit. Ek sal later bietjie meer hieroor uitwei.

Ek wil egter met die volgende statistieke die belangrikheid van die rol wat die plaaslike besture wel moet vervul beklemtoon:

By die bevolkingsensus van September 1960 was die totale bevolking van Transvaal ses en 'n kwart miljoen. Hiervan was drie en ' $n$ half miljoen woonagtig in stedelike gebiede, d.w.s. byna $55 \%$. Van die stedelike bevolking het byna 3,300,000 in gebiede wat onder beheer van plaaslike besture staan gewoon: dit is $96 \%$; of $52 \%$ van die totale bevolking van Transvaal. As daar na die getalle ten opsigte van blankes gekyk word is die verhoudings nog meer opvallend: by dieselfde volkstelling was daar byna een en ' $n$ half miljoen blankes in Transvaal, waarvan meer as een en 'n kwart miljoen in stedelike gebiede woonagtig was, dit is $85 \%$. Hiervan het $1,227,000$ in plaas- 
like bestuursgebiede geval: dit is $98 \%$ van die stedelike blankes.

Ons kan dus sê dat plaaslike besture in Transvaal beheer uitoefen oor die helfte van die totale bevolking van die provinsie en oor vier uit elke vyf blankes in Transvaal. Die doen en late van plaaslike besture, veral op gebied van fisiese beplanning, raak dus 'n baie groot deel van ons bevolking!

\section{Beplanning deur plaaslike owerhede: dorpsbeplanning}

Een van die talryke bevoegdhede en verantwoordelikhede wat deur wetgewing aan plaaslike besture toevertrou is, is dorpsbeplanning.

Die plaaslike besture in Transvaal het egter nie op wetgewing gewag om dorpsbeplanning aan te pak nie. Die beleid om dorpe volgens 'n behoorlike plan uit te lê het plaaslike besture geërf van die Voortrekkers en die eerste intrekkers van Transvaal: ons ou dorpe in Transvaal, waarvan Potchefstroom die eerste en belangrikste was, het nie sommer uit hulle eie gegroei nie maar is eers beplan met inagneming van die mense en hul behoeftes. Hier in Potchefstroom kan ons die resultate daarvan sien: nieteenstaande die drastiese veranderde omstandighede veral ten opsigte van verkeer, is die dorp vandag nog ' $n$ lieflike en aangename plek om in te woon of te besoek.

Ook na die Tweede Vryheidsoorlog, toe die spekulante opgedag het en orals dorpe uitgelê het, veral aan die Witwatersrand, was dit die plaaslike besture wat eerste ingegryp het. Hulle kon nie hierdie opsny van grond keer nie, maar hulle het deur middel van hulle bouverordeninge die grootste foute en die ergste wantoestande probeer bekamp onder andere deur te weier om planne goed te keur wat nie ingepas het by hulle beplanning nie. Van 1907 af het die Provinsie beheer oor uitlê van dorpe begin uitoefen, maar plaaslike besture het nog steeds 'n belangrike taak vervul om die Dorperaad en die Administrateur in te lig en te adviseer oor al die aspekte van 'n nuwe dorp.

Plaaslike besture het ook van hulle ontstaan af 'n positiewe bydrae tot beplanning gelewer deur die verskaffing van dienste en geriewe, die oprigting van geboue, die verskaffing en uitlê van parke en die daarstelling van sportfasi- 
liteite ens. Hierdie munisipale ondernemings speel ' $n$ belangrike rol in die fisiese ontwikkeling van enige dorp. In baie dorpe is hulle gebruik as ' $n$ middel om die ontwikkeling in die regte rigting te lei. Die aanlê van water, elektriese krag, teerstrate en rioolgeriewe is faktore wat baie bydra tot stedelike uitbreiding.

By die meeste plaaslike besture in Transvaal, en veral by die groter stadsrade, was daar egter geen algemene en volledige beplanning op 'n doelbewuste en oorwoë grondslag nie.

In 1931 het die Provinsiale Raad die Dorpe- en Dorpsaanlegordonnansie goedgekeur. Dit was 'n gevolg van herhaalde vertoë wat in die vorige jare gerig is en die verslag en aanbevelings van 'n Komitee uat die hele saak baie grondig ondersoek het. Die vernaamste aspek van daardie Ordonnansie was dat die belangrikste plaaslike besture in Transvaal verplig is om binne drie jaar ' $n$ dorpsbeplanningskema op te stel en enige ander plaaslike bestuur is toegelaat om op eie inisiatief so 'n skema op te stel.

Dit was 'n baie belangrike stap, ' $n$ mylpaal in die geskiedenis van fisiese beplanning in Suid-Afrika. Dinge het nie so vlot verloop as wat aanvanklik verwag is nie: alhoewel alle stadsrade wat verplig was om 'n dorpsbeplanningskema op te stel baie entoesiasties aan die werk gespring het en opnames en ondersoeke ingestel het, is groot moeilikhede ondervind en dit was eers in 1946 dat die eerste skema, naamlik dié van Johannesburg, geproklameer is.

Dit is sekerlik oorbodig om te verduidelik wat 'n dorpsbeplanningskema is. Dit is egter belangrik om daarop te wys dat hierdie stelsel van dorpsbeplanning van die begin af baie omvattend was maar terselfdertyd ook vir klein besonderhede voorsiening gemaak het. Sowel die wyer beplanning van die munisipale gebied, soos die gebruiksbestemming van grond, as die kleiner onderdeeltjies, soos syspasies tussen huise, is daarin opgeneem. Hierdie dorpsbeplanningskemas het, na die groeipyne van die eerste jare, besonder goed gewerk en is vandag, meer as dertig jaar nadat daarmee begin is, nog baie effektief. Hulle getuig van die deeglike werk wat die betrokke plaaslike besture en die raadgewende beplanners verrig het.

Daar is nou 75 plaaslike besture in Transvaal wat geproklameerde dorpsbeplanningskemas het. Daardie plaaslike besture 
het $31,100,000$ inwoners, waarvan $1,170,000$ blankes is. Dit is ongeveer die helfte van die totale bevolking van Transvaal en van $80 \%$ van die blankes van die provinsie. Hierdie syfers bevestig hoe uitgebreid die beplanningsfunksie van ons plaaslike besture is.

Ons kan tereg trots wees op die resultate wat met dorpsaanlegskemas bereik is:

Ons woonbuurtes, wat volgens die tradisionele Suid-Afrikaanse patroon met 'n lae digtheid uitgelê is, vertoon oor die algemeen 'n aantreklike harmonie, sonder die botsende gebruik en lintontwikkeling wat dikwels in ander lande gevind word.

In nuwe dorpe word daar vandag altyd voldoende voorsiening gemaak vir parke en oop ruimtes.

Die merkwaardige toename in woonstelle, wat gedurende die laaste jare opgerig is, het as gevolg van die skemas, op 'n aantreklike manier plaasgevind met baie oop ruimtes tussen die geboue.

Die sentrale gedeeltes van ons dorpe en stede het ordelik ontwikkel, en daar bestaan voorlopig nog geen gevaar dat die middestad vervalle sal raak as gevolg van oorbebouing in 'n beperkte gebied of van kompetisie van buitestedelike winkelsentra nie. Plaaslike owerhede in Transvaal het, oor die algemeen, hulle taak ten opsigte van dorpsbeplanning uitstekend vervul en verdien alle lof. Daardie taak is in goeie hande. Ek kan u die versekering gee dat die Provinsiale Administrasie heeltemal tevrede daarmee is en glad nie planne het om dit van hulle weg te neem of dit in te kort nie; eerder die teenoorgestelde!

\section{Vraagstukke by dorpsbeplanning: veranderde omstandig- hedo}

Ons mag egter nie tevrede wees met wat ons bereik het nie; daar is nog heelwat vraagstukke en moeilikhede in dorpsbeplanning wat ons aandag verg.

Ten eerste het dit nodig geword dat ons ons dorpsbeplanningskemas aanpas by die steeds veranderende omstandighede. Meeste van die ouer skemas is meer as 20 jaar gelede opgestel. Die beplanners het in daardie tyd ruim voorsiening gemaak vir toekomstige ontwikkeling. Hierdie ontwikkeling het nou werklikheid geword, maar ontwikkeling staan nie stil 
nie: dit gaan steeds voort, en wel teen 'n versnellende tempo, veral gedurende die laaste jare.

Ek wil dit dan ook so stel dat die ontwikkeling alreeds op hierdie tydstip die beplanning, soos vasgelê in die eerste dorpsaanlegskemas, ingehaal en in sommige gevalle reeds verby gesteek het. Dit word bewys deur die feit dat Johannesburg reeds met sy twee-honderdste wysigende skema besig is en dat Pretoria vinnig op pad is om die honderdtal te bereik.

Ons moet nie die beplanners blameer wat die oorspronklike skemas opgestel het nie. Ons huidige plaaslike owerhede is self verantwoordelik vir hierdie toestand: dit was en is hulle plig om te beplan. Dit lê op hulle weg om oor die bult te kyk en vooruit die ontwikkeling wat daar gaan kom in die toekoms te bespeur en om dan betyds reëlings daarvoor te tref.

Ten tweede moet ons vasstel hoe die karakter van stede en hulle groei verander.

Die toename in verkeer is natuurlik die skouspelagtigste. Dit is nie nodig om breedvoerig hieroor te praat nie; ons is almal daarvan bewus. Johannesburg en Pretoria het groot planne opgestel om hierdie moeilikhede te bekamp, en ook die ander plaaslike besture is besig om stappe te doen in hierdie verband.

Maar verkeersprobleme is maar net 'n gedeelte van die hele verskynsel. Ek het reeds verwys na die toename in woonstelle. Daar is ook nog die toename in kantoor-akkommodasie: die neiging dat kantoorwerkers baie vinniger toeneem in verhouding tot nywerheidswerkers is oorsee reeds geruime tyd gelede vasgestel en kan nou ook in Suid-Afrika waargeneem word. Ook op nywerheidsgebied het ingrypende veranderings plaasgevind. Die ou voorstelling: dat fabrieke altyd vuil en lelike plekke is wat oorlas veroorsaak deur rook, lawaai en stank, is besig om te verdwyn om plek te maak vir die opvatting dat hulle aantreklike geboue moet wees waar geen steurnis veroorsaak word nie en wat, met die mooi tuine wat daarby aangelê kan word, 'n aanwins vir die omgewing kan beteken.

Ons is bewus daarvan dat die lewenspeil voortdurend styg en dat, met die vermindering van werkure, vryetydsbesteding al hoe belangriker word en aan die vereistes daarvan sal steeds meer aandag geskenk moet word by beplanning. 
Hierdie twee vraagstukke kan nie stuksgewys opgelos word nie. Die tyd het nou aangebreek dat plaaslike owerhede en veral ons groot stadsrade die saak op 'n breë grondslag aanpak. En 'n aangewese manier om dit te doen is om die hooftrekke van die beplanning in 'n "gidsplan" vas te lê.

So 'n plan is eintlik 'n beleidsverklaring van die plaaslike bestuur. Daarin word die oogmerke met ontwikkeling van die gebied neergelê vir 'n tydperk wat oor die volgende 10 tot 20 jaar en langer strek, deur middel van 'n algemene gebruiksbestemming van onontwikkelde gebied, rigsnoere vir 'n funksionele opbou van die middestad, die uitkies van geskikte plekke vir nuwe subsentra en die reservering van strategies geleë terreine vir parke, ontspanningsterreine, skole, hoofpaaie en ander openbare geriewe en dienste.

By die "gidsplan" hoort ook 'n program opgestel te word vir die gekoördineerde uitvoering van munisipale werke in ooreenstemming met die voorgenome ontuikkeling en 'n finansiële program wat die finansiële vereistes en uitwerking van die plan vertolk.

In ons wetgewing op dorpsbeplanning is geen voorsiening gemaak vir hierdie stelsel nie, ook nie in die nuwe Ordonnansie wat in Junie laaslede deur die Provinsiale Raad goedgekeur is nie. Dit was nie omdat ons nie daaraan gedink het nie. Ons het dit nie in die wetgewing opgeneem nie, omdat hierdie stelsel baie buigsaam moet wees en voortdurend by veranderende omstandighede aangepas moet word. Ons het min ondervinding in hierdie rigting en indien ons in die Ordonnansie voorskrifte sou neerlê wat die effek sou hê dat behoorlike verwesenliking van "gidsplanne" bemoeilik word, sou dit die uitvoering daarvan eerder benadeel het as om dit aan te moedig.

Waar egter so 'n gidsplan bestaan sal dit baie nuttig wees as 'n basis om te oordeel oor die wenslikheid en noodsaaklikheid van 'n voorgestelde wysigende dorpaanlegskema. In die nuwe Ordonnansie is wel moontlikhede geskep om wysigende skemas baie vinniger af te handel, en plaaslike owerhede wat 'n gidsplan besit sal ten volle gebruik kan maak van hierdie verkorte prosedure.

Dit is my 'n genoeë om te kan meedeel dat ons twee grootste stadsrade, Johannesburg en Pretoria, reeds die eerste stappe gedoen het wat lei tot die opstel van 'n gidsplan. Ek is baie bly daaroor en ek wens hulle alle sukses met daardie 
belangrike onderneming toe.

\section{Vraagstukke by dorpsbeplanning: stadshernuwing}

Die derde vraagstuk waarmee dorpsbeplanning te doen kry, is stadshernuwing. Ons dorpe en stede in Transvaal was tot nou toe in 'n bevoorregte posisie deurdat hulle min moeilikhede ondervind het met agterbuurtes. Krotwonings (,slums") het wel ontstaan in die woonbuurtes van ons nieblanke bevolking, maar daardie probleem is deur kragdadige optrede van meeste van ons plaaslike owerhede in 'n groot mate bevredigend opgelos, deur middel van die hervestiging van die verskillende rassegroepe in hulle onderskeie groepsgebiede en gesteun deur finansiële hulp en wetgewing van die Sentrale Regering.

Ons het egter nou die stadium bereik dat gedeeltes van ons blanke woonbuurtes oud en vervalle raak en dat dringende aandag daaraan bestee sal moet word. Ek het in die verlede herhaaldelik daarop gewys. Daar is egter nog weinig indien enige resultate in hierdie rigting behaal. Ek is egter bewus daarvan dat die Stadsraad van Johannesburg met 'n aantal projekte besig is, wat moontlik binnekort 'n werklikheid sal word. In Pretoria is die bevolking en grondwaardes meer stabiel, maar ek verneem dat ook daar 'n paar projekte aangepak word.

In die nuwe Ordonnansie wat tydens die jongste sitting van die Provinsiale Raad deurgeloods is, is voorsiening gemaak vir wyer magte met groter moontlikhede aan plaaslike owerhede om herontwikkeling te onderneem. Omdat ons nog nie presies geweet het hoe dit onderneem sal word nie, het ons nie die prosedure noukeurig vasgestel nie. Ons hoop om geleidelik, na mate ons ondervinding met stadshernuwing opdoen, daardie voorsiening uit te brei en duideliker te stel. In die tussentyd behoort dit aan plaaslike owerhede die geleentheid te bied om op 'n meer positiewe wyse op te tree.

\section{Vraagstukke by dorpsbeplanning: die groei van die motro- polis}

Die vierde vraagstuk in stadsbeplanning word geskep deur die voortdurende uitbreiding wat in stedelike gebiede plaasvind. Dit word veral in die groot stede ondervind, waar besighede, kantore, kulturele en opvoedkundige instellings die 
middelpunt vorm van 'n groot bevolkingskonsentrasie. Die magnetisme van die groot stad is 'n wêreldwye verskynsel. Daar is nou vasgestel dat in die Oostelike kusgebied van die Verenigde State van Amerika, in Suidoos-Engeland, en in Noordwes-Europa, dit is in Nederland, België en die Ruhrgebied in Duitsland, groot stedelike streke ontstaan het waarvan die stede en dorpe so aanmekaar en deurmekaar gestrengel is dat dit moeilik word om hulle as aparte eenhede te onderskei. Uitbreiding van die groot stede vind plaas buite die munisipale grense van daardie stede, dikwels in die gebied van aangrensende plaaslike owerhede. Dit het gelei tot die ontstaan van die begrip "metropolis-streek" of ook "megalopolis".

Hier in Suid-Afrika het daardie verskynsel ook reeds tevoorskyn getree, veral in Suid-Transvaal. Die bevolkingsametrekkings in ons land is nie so groot as oorsee nie, maar weens ons tradisionele voorkeur vir enkel huise en groot erwe en weens die hoë lewenspeil van ons blanke bevolking het die verskynsel reeds sulke afmetings aangeneem dat dit met oorsese ontwikkeling vergelyk kan word. Pretoria het sedert die laaste wêreldoorlog ver oor sy grense uitgebrei en die aangrensende munisipaliteite Silverton en Pretoria-Noord was naderhand nog net voorstede van die hoofstad.

Baie probleme, veral op die gebied van fisiese beplanning, het daaruit ontstaan. Soos $\mathbf{u}$ weet is die moeilikhede opgelos deur die uitbreiding van Pretoria se grense om die "Groter Pretoria" te vorm. Hierdie ingrypende wysiging van grense het besonder glad verloop, en die ondervinding wat daarmee opgedoen is, behoort van groot voordeel te wees by die behandeling van dergelike komplekse in die toekoms.

Die belangrikste metropolis-streek in ons provinsie, en ook in ons land en selfs op die vasteland van Afrika, is die Witwatersrand. Die feit is reeds jare gelede vasgestel, onder andere, deur die Raad vir Ontwikkeling van Natuurlike Hulpbronne wat baie aandag daaraan bestee het met sy streekopname van Suid-Transvaal in die jare 1954 tot 1957.

Daar bestaan meningsverskille oor die kwessie of die hele Pretoria-Witwatersrand-Vereeniging-gebied 'n stedike streek vorm, of net die Witwatersrand, of selfs net die sentrale gedeelte daarvan. Maar daar bestaan nie die minste twyfel nie dat Johannesburg en die aangrensende gebiede een groo! stedelike eenheid vorm. 'n Groot gedeelte van die inwoners van die munisipaliteite Roodepoort, Randburg, Edenvale, 
Bedfordview, Germiston en Alberton en van die plaaslike gebiede van die Gesondheidsraad vir Buitestedelike Gebiede, wat ten noorde en ten suide van Johannesburg geleë is, werk in die middestad van Johannesburg en is van Johannesburg se sentrale besigheidsentrum afhanklik vir inkopies van luukse artikels en georganiseerde ontspanning.

Die fisiese beplanning van die metropolis Johannesburg kan nie beperk word tot sy munisipale grense nie. Reeds nou onderneem die Stadsraad van Johannesburg werke en verskaf hy geriewe aan die bevolking buite sy grense. Daar is byvoorbeeld rioolsuiweringswerke, streeksparke en 'n skouburg, wat die inwoners buite sy eie gebied bedien, maar ook sy busdiens en elektrisiteitsvoorsiening oorskry die munisipale grense. Die behoefte aan snelweë het ook tot 'n groot mate ontstaan as gevolg van die voertuie wat van aangrensende gebiede instroom.

Beplanning vir Johannesburg behoort dus ook beplanning vir die aangrensende gebiede te wees. Dit het verlede jaar weer duidelik geword toe die Administrateur-in-Uitvoerende Komitee voor moeilike beslissings geplaas is om te besluit of groot woonstelgebiede en kleiner erwe, toegelaat moet word in die streek ten noorde van Johannesburg. Die ondersoek van hierdie vraagstuk is nog nie voltoai nie en dit is dus nog te vroeg om iets daaroor te sê.

Dit is egter duidelik dat administratiewe grense 'n groot rol speel by fisiese beplanning.

In watter rigting die oplossing van Johannesburg se beplanningsprobleme gevind sal word kan ek nie sê nie. Die Departement van Plaaslike Bestuur is nou besig met 'n ondersoek insake die grense van plaaslike besture aan die noordeen oostekant van Johannesburg, en ons sal moet wag om te verneem wat daar bevind sal word.

Maar wat die voorstelle ook al gaan wees, ons moet besef dat ons nie kan staatmaak op vrywillige samewerking nie. Vrywillige samewerking sou die mooiste en maklikste oplossing wees, maar ondervinding het ons geleer dat dit slegs suksesvol is tot die oomblik wanneer belange begin bots. Daar is baie voorbeelde hiervan maar ek wil slegs twee noem.

Die eerste is die Gesamentlike Beplanningskomitee vir die Witwatersrand, wat na die proklamasie van die Dorps en Dorpeaanlegordonnansie saamgestel is om die beplanning van die dorpe aan die Witwatersrand te koördineer op 'n 
streeksbasis. Hierdie Komitee het uitstekende werk verrig totdat daar groot moeilikhede waarin botsende belange betrokke was, opgeduik het. Een van daardie moeilikhede was die plasing van Bantoewoondorpe op 'n streeksbasis. Die Komitee se bestaan het dan ook tot 'n end gekom in die begin van die vyftiger jare.

Die ander voorbeeld is die samewerking tussen die Stads. raad van Pretoria en die Gesondheidsraad vir Buitestedelike Gebiede en ander plaaslike owerhede vir die verskaffing van noodsaaklike dienste soos water, elektrisiteit, riolering en brandweer. Die moeilikhede wat daarby ontstaan, het tot 'n groot mate bygedra tot die totstandkoming van Groter Pretoria.

Waar samewerking tussen plaaslike besture vereis word, is dit gewoonlik nodig dat die Provinsie, as die hoër gesag, toesig daaroor hou en optree wanneer daardie samewerking nie vlot verloop nie. In daardie opsig kan die sterk gevoel van onafhanklikheid of outonomie waarna ek in die begin verwys het, somtyds 'n groot struikelblok wees.

Die provinsiale owerheid word soms daarvan beskuldig dat hy nie groter vryheid en magte afstaan aan plaaslike besture nie. Dit was en is nog altyd die beleid van die Uitvoerende Komitee om plaaslike sake sover moontlik in die hande van plaaslike mense te laat. Maar dit is die provinsie se verantwoordelikheid en plig om toe te sien dat die algemene belange van die plaaslike gemeenskappe nie daaronder ly nie. En waar plaaslike owerhede om watter rede ook al, daardie belange veronagsaam moet die provinsie optree. Dit is dan ook nodig om gedurig die verrigtinge van alle plaaslike owerhede dop te hou om seker te maak dat niks verkeerd gaan nie.

Ek is daarvan oortuig dat hierdie waaksame oog veel bygedra het tot die hoë peil wat plaaslike bestuur in Transvaal bereik het en steeds handhaaf.

Die beplanning van 'n stedelike streek, wat onder die beheer van 'n aantal plaaslike owerhede staan, is in werklikheid streekbeplanning. En waar daardie plaaslike owerhede bestaan uit 'n groep sterk, eenhede met aparte kerne, maar wat so uitgebrei en ontwikkel het dat hulle 'n aaneengeskakelde stedelike gebied vorm waar munisipale grense feitlik kunsmatig geword het en die werklike fisiese grense moeilik bepaal kan word, daar is streekbeplanning 'n dringende noodsaaklikheid.

Die doel van daardie streekbeplanning moet 'n ewewigtige 
en harmonieuse ontwikkeling wees waarby vir alle dele die moontlikhede geskep word waarop hulle geregtig is. Dit kan nie toegelaat word dat een gebied ontwikkel ten koste van ' $n$ ander nie. Dit is die plig van die provinsie om te verseker dat daardie beginsel toegepas word.

Die provinsie se taak ten opsigte van dorpsbeplanning bestaan uit toesig en koördinasie. Maar wanneer daardie dorpsbeplanning 'n streekskarakter kry moet daardie taak uitgebrei word na 'n aktiewe deelname aan die beplanningsproses.

\section{Streekbeplanning}

En nou kom ek tot die aspek van fisiese beplanning waarin ons almal baie belangstel, naamlik: streekbeplanning.

Die verskil tussen stads- en streekbeplanning is deur $\mathrm{dr}$. John Friedman in "Land Economics" (Februarie 1956) soos volg gestel:

„The contrast between city and regional planning may be summarized by saying that city planning has been primarily concerned with community conservation through land use planning and control, while the purpose of planning for regions has been economic progress through the development of natural resources."

Indien ons hierdie stelling aanvaar staan metropolisbeplanning, waarvan ek so pas gepraat het, halfpad tussen Stadsbeplanning en Streekbeplanning. Maar u sal ongetwyfeld met my saamstem dat streekbeplanning vir ekonomiese vooruitgang, deur ontginning van natuurlike hulpbronne, baie nuttig kan wees en moontlikhede vir ontwikkeling aansienlik kan bevorder.

Dit is my mening dat streekbeplanning so gou moontlik aangepak behoort te word sodat ook die plattelandse streke mag deel in die welstand wat deur ons land se vinnige ontwikkeling bereik word.

Uit die voorgaande sal dit vir $u$ duidelik wees dat dit my oortuiging is dat streekbeplanning in die eerste plek die taak en verantwoordelikheid van die provinsie is. Hoe die provinsies streekbeplanning onderneem sal 'n ander spreker vir u skets. Ek wil my bepaal by die aandeel wat plaaslike owerhede by streekbeplanning kan hê.

Ek het reeds aangetoon dat in ons metropolis-streke die plaaslike owerhede in samewerking met en onder toesig van 
die provinsie 'n belangrike beplanningsfunksie kan uitoefen

In die ander streke sal plaaslike owerhede ook 'n belangrike rol kan vervul. Dit is ' $n$ gedagte wat al hoe meer aanvaar word dat 'n streek bestaan om 'n stedelike kern of kerne, met ander woorde: as daar nie 'n stad of dorp as 'n sentrale plek of plekke is nie, dan is daar ook nie 'n streek nie. Miskien kan die streek beskryf word as die liggaam en die stad wat daarbinne geleë is as die hart.

Dr. Friedmann, in die uiteensetting waarna ek reeds verwys het, het dit soos volg gestel:

„.... the city region has, in fact, become the basic areal unit for carrying out comprehensive development planning below the national level".

By die ondersoek van streke en die beplanning daarvan sal daardie sentrale plekke baie belangrik wees. Die betrokke plaaslike owerhede sal baie kan bydra tot daardie ondersoek en beplanning deur deel te neem aan die werksaamhede. Maar buitendien sal hulle ook geraadpleeg word in alle sake betreffende die fisiese beplanning van hulle streke.

Om op te som dus, kan die begrip "fisiese beplanning" miskien die beste beskryf word as die verordening en reëling van 'n dorp of gebied met die doel om te verseker dat die ontwikkeling inpas by 'n voorafbepaalde ,gidsplan" wat, hoewel dit afdwingbaar is, tog buigbaar genoeg moet wees om aangepas te word by veranderde omstandighede. Doeltreffende beplanning bchoort altyd as doel te stel die skepping van omstandighede waarin die ontginning van die streek of land se hulpbronne die voordeligste kan geskied asook vir die vestiging en ontwikkeling van sy nywerhede. Dit moet ook toesien dat die vestiging van bevolking in dorpe of streke so geskied dat gesonde, ordelike en gelukkige stedelike gemeenskappe geskep word sonder administratiewe, sosiologiese en etnologiese vraagstukke. In die Republiek van Suid-Afrika is die taak van beplanning dan ook ingewikkelder as in die meeste ander lande deurdat ons hier te doen het met ' $n$ veelrassige gemeenskap en 'n aanvaarde en tradisionele beleid van afsondering wat die versigtige en tydige beplanning van woongebiede 'n absolute vereiste maak.

Ek dink u sal met my saamstem dat plaaslike bestuur nie 'n leidende rol in streekbeplanning moet vervul nie maar dat die sukses en effektiwiteit van streekbeplanning tot 'n groot mate sal afhang van die belangstelling en samewerking wat 
van plaaslike besture ontvang word. Ek vertrou dan ook dat ons stads- en dorpsrade uit eie beweging hulle samewerking sal aanbied wanneer die Provinsiale Administrasie ernstig met hierdie groot taak van streekbeplanning begin. So 'n samewerking moet sy vrugte afwerp en kan nie anders as om by te dra tot die bereiking van die doelwitte wat ons in ons beplanning gestel het nie. Hierdeur kan ons ons ideale verwesenlik sien en iets nalaat vir ons nageslagte waarop hulle trots kan wees.

P. Z. J. van Vuuren, L.U.K.

Johannesburg. 